method can be used to determine amounts as small as $10^{-10} \mathrm{~g}$.

Changes in the vascular bed in the web of a frog's feet in vivo in areas $200 \mu$ across, have been examined by determining changes in iron present in different conditions. The total amount of iron in the area analysed is measured for a period of $1 / 2 \mathrm{~min}$. Most of the iron analysed is due to the hemoglobin present in the erythrocytes, and variations in the serum iron are relatively unimportant.

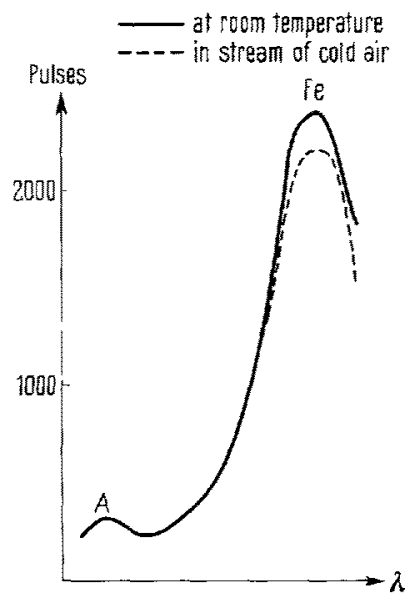

The experiments are performed in air with the specimen fixed in relation to the proportional counter. A peak representing argon in the air is used as a reference. Expression of the results in ratios Fe/A makes them independent of variations in intensity of the primary beam. If a very small drop of iron solution of known concentration and volume is analysed, the results can be expressed in $g$ per analysed area (Long and Röcke:RT ${ }^{1}$ ). The curve shown (Figuro) illustrates the change within a circular area of $200 \mu$ diameter measured at room temperature and during exposure to a stream of cold air.

Resumé. Une méthode d'analyse quantitative du fer dans l'hémoglobine a été développée, utilisant la fluorescence aux rayons $\mathrm{X}$. Elle est appliquée à des tissus vivants pour l'enregistrement de changements très faibles dans la circulation sanguine dans des fragments microscopiques.

\section{H. RÖCKERT}

Depayment of Histology, University of Goteborg (Sweden), September 4, 1964.

2 J. V. P. Long and H. O. E. Röckert, Third Internat. Symp. $\mathrm{X}$-ray Optics and $\mathrm{X}$-ray Micronalysis, Stanford 1902 (Academic Press, 19633 .

\section{A Novel Mass Culture of Entamoeba histolytica on Nutrient Agar}

BoECK and Drbohlav ${ }^{1}$ in 1925 accidentally discovered pathogenic amoebae in a flagellate culture from infected stool material. The culture medium consisted of a solid slant with a liquid overlay. Completely liquid culture media were then introduced and later an essentially synthetic medium by HANSEN and ANDERSON ${ }^{2}$.

In 1958 a hartmannellid (?) free-living amoeba macroscopically contaminating a blood-agar culture of Staphylococcus albus was isolated by the author. This amoeba, subsequently re-isolated on several occasions from human stool material, proved to be of great value in the assay of amoebicides ${ }^{3}$. The present work - an offspring of the work of 1958 and the following years - witnesses the entry of Entamoeba histolytica into a new age, the age of solid media.

Methods. Sterile nutrient agar containing $0.2 \%$ dextrose and $0.7 \%$ table salt is used throughout. Plates or slants are overlaid with an egg white-agar-rice powderamoeba-blood mixture, prepared as follows: Sterile egg white is warmed to $55-60^{\circ} \mathrm{C}$ in a water bath and $7 \mathrm{~cm}^{3}$ of melted nutrient agar, cooled to about $60^{\circ} \mathrm{C}$, is added to $30 \mathrm{~cm}^{3}$ of the warm egg white and well homogenized with it. $6-8 \mathrm{~g}$ of sterile rice powder are then added and well dispersed with the aif of sterile glass beads. A boiled saline suspension of the free-living amoeba mentioned above, obtained from 10-15 Petri dish cultures, is added in addition to $5-10 \%$ defibrinated human blood. Nutrient agar previously prepared in the Petri dishes or tubes with a homogeneous mixture is overlaik. Tubes are put in a slanting position. In a tew moments the overlay will not trickle on tilting the plate or holding the tube in the upright position. The medium is now ready for use.

Mucus and blood from four cases of acute amoebic dysentery were inoculated in the centre of the plate medium. Two more cases of dysentery containing Trichomonas hominis and pus cells but no amoebae were also inoculated in the centre of the plates. The inoculated media were immediately incubated at $37^{\circ} \mathrm{C}$ under anaerobic conditions using alkaline pyrogallol as an oxygen absorbing agent. Subcultures were made every $48-72 \mathrm{~h}$.

Results. Entamoeba histolytica, morphologically indistinguishable from amoebae found in acute dysentery, grew luxuriantly in four out of four cases of acute amoebic dysentery. Trichomonas hominis grow in clusters in two out of two stools infected with this flagellate.

Résumé. Une nouvelle méthode de culture de Entamoeba histolytica et Trichomonas hominis sur plaques d'agar est employée ici avec succès.

K. A. YOUSSEF

Ministry of Health, Cairo (Egypt), July 27, 1964.

1 W. C. Boecr and I. Drbohlav, Am. I. Hyg. 5, 371 (1925).

2 E. L. HANSEN and H. H. Avderson, Parasitology 39,69 (1948).

3 K. A. Youssef, Exper. 20, 463 (1964).

4 Present address: 37 , Kasr El Aini St., Cairo (Egypt). 